Pak. j. sci. ind. res. Ser. B: biol. sci. 201356 (1) 23-28

\title{
Poisoning by Plants in the Taza-Al Hoceima-Taounate Region in Morocco
}

\author{
Toilabiya Loutfia ${ }^{\mathrm{a} *}$, Hami Hinde ${ }^{\mathrm{a}}$, Soulaymani Abdelmajid ${ }^{\mathrm{a}}$, Rhalem Naima ${ }^{\text {ab }}$, Ouammi \\ Lahcen $^{\text {b }}$, Benali Doha ${ }^{a}$, Mokhtari Adbelrhani ${ }^{a}$ and Soulaymani-Bencheikh Rachida ${ }^{\text {bc }}$ \\ ${ }^{a}$ Laboratory of Genetic and Biometry, Faculty of Sciences, Ibn Tofail University, Kénitra, Morocco \\ ${ }^{b}$ Poison Control Centre of Morocco, Rabat, Morocco \\ ${ }^{c}$ Faculty of Medicine and Pharmacy, Mohammed V University, Rabat, Morocco
}

(received September 20, 2011; revised September 7, 2012; accepted September 12, 2012)

\begin{abstract}
A descriptive retrospective-study was carried out on poisoning cases by plants in Taza-Al Hoceima-Taounate region in Morocco, reported between 1984 and 2007 to the Moroccan Poison Control Centre. During this period, 104 cases of poisoning were recorded. Atractylis gummifera was the most incriminated plant. The average age of poisoned patients was $11 \pm 7.8$ years. The sex ratio $(\mathrm{M} / \mathrm{F})$ was 0.9 . According to the data, poisoning by plants was primarily responsible for gastrointestinal system disorders, nervous system attacks, visual disorders and heart failure. A lethality rate of $33.65 \%$ was recorded, with a total of thirty-five deaths.
\end{abstract}

Keywords: poisoning plants, Atractylis gummifera, Morocco, lethal effect

\section{Introduction}

Plants are used for their therapeutic and nutritional properties throughout the world. According to WHO, $80 \%$ of the population in some countries of Asia and Africa use traditional medication for their basic health care (Bagnis et al., 2004). In the economically disadvantaged countries, consumption of wild plants is part of diet habits, which are also used in traditional medicine (Lengani et al., 2010). According to the 2003 annual report of the American Association of Poison Control Centres, the plants are the cause of $3.2 \%$ of all poisonings in the United States of America. A study was conducted in the Poison Control Centre of Strasbourg between 1989 and 2003; it revealed 4808 poisonings by plants, counting for $5 \%$ of all recorded cases (Flesch, 2005). The Mediterranean countries are well known for their significant plant biodiversity, most particularly Morocco. From 1980 to 2007, the Poison Control and Pharmacovigilance Centre of Morocco has recorded 2558 cases of poisoning by plants, counting for $3.3 \%$ of all poisoning cases reported in Morocco, with a lethality rate of $7 \%$.

Atractylis gummifera is used in the dried form, in traditional medicine for its healing properties for local application

*Author for correspondence; E-mail: loutfia10@hotmail.com (syphilis, furuncle, abscess), in the form of herbal as a diuretic, purgative, antipyretic, abortive and emetic (Skalli et al., 2002; Chardon et al., 1964). All parts of the plant contain toxic compounds, but at lower concentrations from root to leaf and in between, through the stalk, the bracts, flower and the seed (Benkirane, 1994).

The high frequency of poisoning among children can be explained by the similarity of A. gummifera in wild artichoke (Cynara humilis), or edible Asteracae (Cartina acaulis) or the thistle of Spain (Scolymus hispanicus) (Bellakhdar, 1997). This confusion was highlighted by a study in the province of Badajoz in Spain over the last 10 years, which showed that only $5 \%$ of the population was able to recognize the plant (Vallejo et al., 2008).

Euphorbia resinifera is an abundant plant in the Moroccan Anti-Atlas region. Everywhere in Morocco, the resin of Euphorbia is used as a revulsive in combination with the resin canal (resiniferatoxin). For local applications, kneaded with flour or semolina and egg white and used in the treatment of rheumatisms, paralysis and in the care of stings and venomous bites (Bellakhdar, 1997). Resiniferatoxin is a strong irritant diterpene present in the latex of the plant, which reduces toothache or chronic pain; it interacts with a specific site of recognition sites of the membrane (vanilloid 
receptor) (Appendino and Szallasi, 1997). The latex of this plant, either fresh or dried, is a dangerous product. Accidents happen especially to resin collectors or to people who have used the resin as a medicine or as an abortive. Ingestion of $0.5 \mathrm{~g}$ of the resin causes serious inflammation of the mucous membranes of the digestive tract with gastroenteritis. At higher doses, it causes generalized digestive inflammation with gastrointestinal ulcers, arrhythmia, convulsions, hematuria and in very severe cases death by asphyxiation (Bellakhdar, 1997).

Artemisia absinthium is frequently used in Morocco as an infusion with tea, especially in winter. This plant is considered as vermifuge, antiseptic, antimalarial, aperitif, eupeptic, diuretic, vulnerary and also as an active ingredient against amenorrhoea and leucorrhoea (Fournier, 1947; Cazin, 1876). The liquor extract made from the plant (absinthe) induces clinical effects where the nervous disorders dominate. Toxicity was especially attributed to the compounds present in the thujone of the essential oils of the plant (Vogt, 1981). Bonkovsky et al. (1992); Zain et al. (2008) have shown that thujone like $\alpha$-pinene and camphor present in the essential oil of absinthe can be hepatotoxic. Other plants that caused poisoning in this region are Peganum harmala, Mandragora automnalis, Carthamus tinctorius, Warionia saharae, Ricinus communis and Rosmarinus officinalis.

P. harmala (Zygophyllaceae) is found in the whole country, used as fumigant to calm screaming and insomniac children. The seeds are used against jaundice, haemorrhoids, intestinal pain, heart diseases, female infertility and uterine diseases. It is used to treat infant toxicoses and childhood diarrhoea, joint pain, rheumatic disorders and sciatica. Seed powder is a healing for circumcisions. Roots are used against gingivitis. Decoction of seeds is used as abortive. The plant contains $4 \%$ alkaloids in seeds and 3\% in roots. Vasicine has the structure of quinazoline; harmaline $(2.1 \%)$, harmine (1.6\%); and harmalol became tryptamine. Alkaloids are responsible for the toxicity, have in common, an indole nucleus and contain an important molecule for the function of nervous system (serotonin). Pelt (1971) reported that indole structure has hallucinogenic activity. These alkaloids have a cardiovascular action as hypotension, arrhythmia, bradycardia (Aarons et al., 1977) and oxytocic (Paris and Moyse, 1976-1981).

M. automnalis (Solanaceae) is a native plant of Mediterranean countries. In the rural area of Casablanca and Rabat, the root is sprayed as narcotic; as fumigant in genitals to treat women diseases. Smoked roots and leaves treat asthma and hay. Fruits are used by women to gain weight. Charnot (1945) gave an analeptic recipe from root powder. Formerly, the plant was widely used as a sedative, an anesthetic and a narcotic for amputations. The plant contains tropane alkaloids such as atropine, hyoscyamine and scopolamine (Paris and Moyse, 1976-1981). These alkaloids can cause dizziness, vomiting, heaviness in legs and staggering gait, dry mouth, thirst, dilated pupils, decreased visual acuity and purple face.

C. tinctorius (Asteraceae) is a plant grown in Morocco, its flowers are used for eye drops, and in lotion for skin diseases and against jaundice. Formerly, flowers were used by women to prepare makeup. The petals are used for dyeing and making ink for writing. Flowers contain two colouring substances: carthamine and isocarthamine. By hydrolysis, they release glucose and carthamine or isocarthamine. By enzymatic oxidation, carthamine becomes red carthamone. Yellow pigments are also found. These are yellow safflor A, yellow safflor B and derivatives carthamine. Safflower oil contains $90 \%$ of unsaturated fatty acids and $10 \%$ of saturated acids (Bellakhdar, 1997).

$W$. saharae (Asteraceae) is a small tree with strong odour, endemic to Morocco and to the Oran sahara. Leaves are used against rheumatic pains, jaundice, epileptic seizures and cervix diseases. The essential oil obtained from the leaves contains three main products: eudesmol (42.2\%), linadol (8.6\%) and nerolidol (17.2\%) (Ramaut et al., 1985). R. communis (Euphorbiaceae) is a plant of the East of Morocco, leaves are used as an emmenagogue and hemostatic for small wounds. Ricin oil and whole seeds in small doses are purgative. Dried flowers mixed with honey are used in diarrhoea. Ricin oil mixed with leaves of $W$. saharae, are used to treat rheumatism and paralysis. Seed contains $10 \%$ carbohydrates; 45 to $50 \%$ of fatty oil; $5 \%$ of protein; alkaloid with low toxicity (ricinine); enzyme (lipase); uric acid; glutamine; amino derivatives and glycoprotein as allergen. Ricin oil contains ricinoleic, oleic, linoleic, stearic and dihydro stearic acids. Ricine is the active principle responsible of toxicity.

R. officinalis (Lamiaceae) is a Mediterranean plant common in the East of Morocco. Leaves are used as aperitif, cholagogue and stomachic and its powder is used as healing and antiseptic for circumcision. This plant is an emmenagogue. Its essential oil contains l' $\alpha$-pinene ((7-80\%), verbenone (1-37\%), camphor 
(1-35\%), eucalyptol (1-35\%), borneol (4-19\%), bornyl acetate $(10 \%)$ and camphene. At high doses, the plant causes irritation, gastrointestinal hemorrhage, hepatic and kidney diseases and epilepsy (Bellakhdar, 1997).

This study is the first one conducted in Taza-Al HoceimaTaounate region because in this region, this poisoning has been the subject of several declarations and a significant number of lethality cases (Ouammi et al., 2009) due to plants. The study established the profile of people poisoned by plants, identified the species that have caused more deaths and determined risk factors that may influence the prognosis of patients. This will allow a better awareness and management of the people poisoned in Morocco, especially in the Taza-Al Hoceima-Taounate region.

\section{Materials and Methods}

A descriptive retrospective-study covering all cases of poisonings recorded between 1984 and 2007 in health services in the Taza-Al Hoceima-Taounate region was conducted. The Taza-Al Hoceima-Taounate region is located north of Morocco along the Mediterranean coast between $34^{\circ} 00^{\prime}$ and $35^{\circ} 30^{\prime}$ of latitude and $03^{\circ} 00^{\prime}$ and $04^{\circ} 30^{\prime}$ longitude. Its area is $24155 \mathrm{~km}^{2}$. In 2007, the population of this region was 1828897 inhabitants according to the General Population and Habitat Census. The population density was $74.81 \mathrm{inhab} / \mathrm{km}^{2}$ (Fig. 1). Data on poisonings reported between 1984 and 2007 was collected on declaration forms by health professional in-charge of patients (doctors or nurses). The study included all patients who appeared intoxicated at a health structure of the study area. Poisoned patients by more than one product and those who appeared at a health structure other than that of the ministry of health were not taken into account.

The data was entered into Excel and statistical analysis was performed using Epi-Info software. Analysis

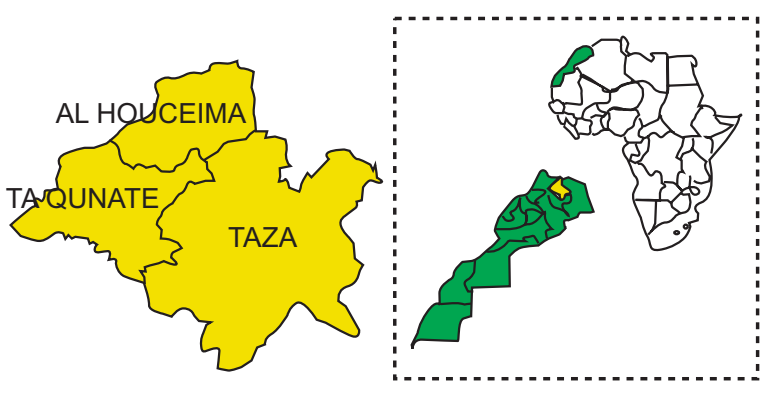

Fig. 1. Geographic location of the Taza-Al Hoceima-Taounate region, Morocco. concerned the description of patient characteristics (age, sex, origin, and province) and poisoning (year, month, place and circumstances of poisoning, symptoms, treatment and vital prognosis). The influence of different factors on the evolution of poisoned patients was analyzed and discussed in this work by calculating the relative risk (RR).

\section{Results and Discussion}

During the study period, 104 cases of poisoning by plants were collected. The sex ratio $(\mathrm{M} / \mathrm{F})$ was in favour of females (0.9).

The average age of poisoned patient was of $11 \pm 7.8$. Distribution data of poisoning cases according to age is grouped in Table 1. The age group between 5-15 years was the most affected (64.4\%). According to the distribution results of the poisoning cases based on provinces, Taza province was declared with highest poisonings cases $(45.2 \%)$, then the province of Taounate (42.3\%) and the province of Al Hoceima (12.5\%). The statement was important in rural areas $(26.9 \%)$ and only $1.9 \%$ in urban area. Year wise distribution of poisoning shows that the majority of statements were recorded in 1993 (20 cases) and 1996 (35 cases) (Fig. 2a). The results show a high frequency of poisoning during the

Table 1. Distribution of poisoning cases according to characteristics of patients.

\begin{tabular}{ll}
\hline \hline Characteristic & Number of declaration (\%) \\
\hline Age groups in years & \\
$1-5$ & - \\
$11(10.6)$ & $67(64.4)$ \\
$5-15$ & $7(6.7)$ \\
$15-20$ & $13(12.5)$ \\
$20-75$ & $6(5.8)$ \\
Unknown & \\
Sex & $47(45.2)$ \\
Male & $52(50)$ \\
Female & $5(4.8)$ \\
Unknown & \\
Province & $47(45.2)$ \\
Taza & $13(12.5)$ \\
Al Hoceima & $44(42.3)$ \\
Taounate & \\
Area & $2(1.9)$ \\
Urban & $28(26.9)$ \\
Rural & $74(71.2)$ \\
Unknown & \\
\hline \hline
\end{tabular}


months of May (15 cases), June (14 cases) and July (15 cases). This corresponds with the spring season, a cool period when the flowering is high (Fig. 2b). Atractylis gummifera, with 71 cases, was the most incriminated plant and caused the highest deaths (30 cases). Euphorbia resinifera and Artemisia absinthium were the two other species each of which caused one death (Table 2).

Various symptoms of patients included gastrointestinal ( 80 cases), neurological ( 28 cases), visual (22 cases) and cardiac (17 cases) (Table 3$)$.

The poisoning was most often accidental; however, 6 cases of suicidal attempts ( 2 men and 4 adult females) were noted. Suicidal attempt cases concerned the use of $C$. tinctorius (1 case), P. harmala (2 cases), $R$. communi (1 case), W. saharea (1 case) and another case in which the name of the plant was not mentioned. Most of the patients received an evacuator and symptomatic
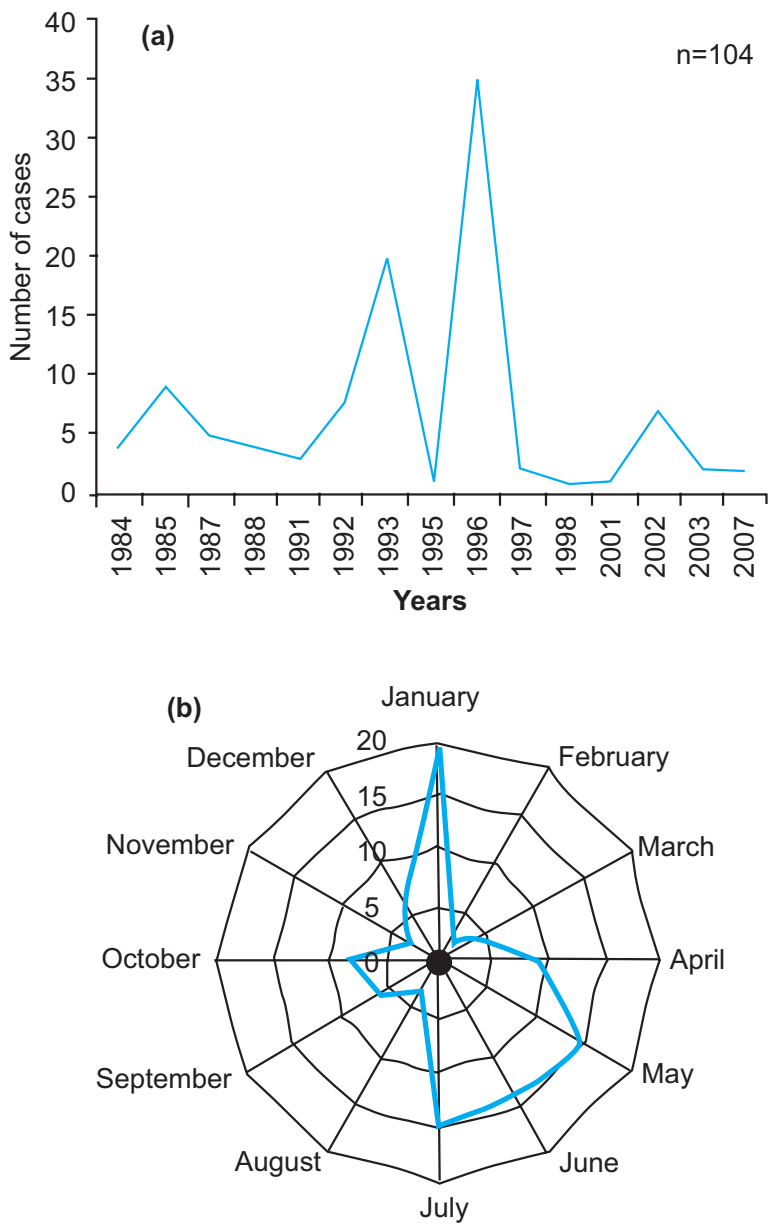

Fig. 2a-b. Distribution of poisoning in time. a: years; b: months. treatment (gastric pump), with a case of therapeutic abstention.

The status of 67 patients was known. The prognosis was fatal in 35 cases, with a lethality rate of $33.65 \%$. The number of poisoned children below 15 years was 78 cases; the number of children who died was 31 . The specific lethality rate was of $39.7 \%$. The effect results of different factors [gender, age $(=15$ or $>15$ years $)$ ] circumstances (accidental or voluntary), clinical status (symptomatic or asymptomatic), type of poisoning (isolated or collective) and origin of patients (urban or

Table 2. Incriminated plants, number of poisoning and deaths

\begin{tabular}{lll}
\hline \hline Species & $\begin{array}{l}\text { Number of } \\
\text { poisoning }\end{array}$ & $\begin{array}{l}\text { Number of } \\
\text { deaths }\end{array}$ \\
\hline Euphorbia resinifera & 1 & 1 \\
Warionia saharae & 1 & - \\
Rosmarinus officinalis & 1 & - \\
Ricinus communis & 1 & - \\
Mandragora autumnalis & 2 & - \\
Carthamus tinctorius & 3 & - \\
Peganum harmala & 3 & - \\
Artemisia absinthium & 4 & 1 \\
Atractylis gummifera & 71 & 30 \\
Unknown & 17 & 3 \\
\hline Total & 104 & 35 \\
\hline \hline
\end{tabular}

Table 3. Distribution of poisoning cases according to clinical signs

\begin{tabular}{ll}
\hline \hline Clinical signs & Number of cases (\%) \\
\hline Gastrointestinal system affections & $80(48)$ \\
Central and peripheral nervous & \\
system disorders & $28(17)$ \\
Visual system disorders & $22(13)$ \\
Disorders of rate and cardiac rhythm & $17(10)$ \\
Affections of respiratory & $7(4)$ \\
Affections of musculoskeletal system & $6(4)$ \\
General health disorders & $4(2)$ \\
Affections of platelets, bleeding & \\
and clotting & $2(1)$ \\
Urinary system disorders & $1(1)$ \\
\hline Total & $* 167(100)$ \\
\hline
\end{tabular}

*The total numbers of signs exceeded of the total number of poisoning; because some patients had a combination of several signs 
rural) on the evolution of patients showed that only the origin of the patients presented significant association with death. Rural origin may increase the risk of evolution into the death; relative risk was $0.217\left(\mathrm{CI}_{95} \%\right.$ : 0.100-0.472) (Table 4).

Table 4. Influence of some factors on evolution of patients

\begin{tabular}{lllll}
\hline \hline Characteristics & Healing Deaths & $\begin{array}{l}\text { Relative } \\
\text { risk }\end{array}$ & $95 \%$ CI \\
\hline Age & & & & \\
$\quad$ Child & 27 & 31 & 2,296 & $0,390-13,536$ \\
$\quad$ Adult & 4 & 2 & & \\
Sex & & & & \\
$\quad$ Female & 16 & 19 & 1,357 & $0,510-3,609$ \\
$\quad$ Male & 16 & 14 & & \\
$\begin{array}{l}\text { Clinic } \\
\quad \text { Symptomatic }\end{array}$ & 21 & 29 & 2,532 & $0,808-7,934$ \\
$\quad$ Asymptomatic & 11 & 6 & & \\
$\begin{array}{l}\text { Poisoning type } \\
\quad \text { Isolated }\end{array}$ & 26 & 29 & 1,115 & $0,320-3,890$ \\
$\quad$ Collective & 6 & 6 & & \\
Origin & & & & \\
$\quad$ Rural & 5 & 18 & 0,217 & $0,100-0,472$ \\
$\quad$ Urban & 1 & 0 & & \\
\hline \hline
\end{tabular}

$\mathrm{CI}=$ confidence interval of the relative risk.

According to the reported data, poisoning by plants had affected many more children whose age was less than 15 years. This is in accordance with results found in France by Meyer (1989). Statements of poisoning were higher in rural areas and more frequent during cool periods that promote development and flowering of plants (Soulaymani et al., 2006; Charnot, 1945). The majority of poisoned patients showed disorders of gastrointestinal and central and peripheral nervous systems. Similar results were noted by (Hami et al. 2011). Another clinical study showed that symptoms of poisoning by Atractylis gummifera were mainly diarrhoea, vomiting, pain and abdominal bloating. The most serious forms were identified as neurological disorders (profound coma), thermoregulation disorders (hypothermia initial), cardiovascular disorders (rapid heartbeat, irregular blood pressure, terminal collapsus), respiratory disorders, severe hepatic dysfunction and renal failure (Masri et al., 2009). In this study $A$. gummifera was responsible for $68 \%$ of poisoning cases causing 30 deaths in the area covered by this study. Several cases have also been reported in Tunisia (Hamouda et al., 2004) and in other regions of Morocco (Hami et al., 2011). Isolated cases were also reported in Italy (Santi and Cascio, 1955), Spain (Salas et al., 1985) and Greece (Kairis, 1996).

Toxic compounds are the actractyloside (atractylate of potassium) and carboxyatractyloside (gummiferine), which are inhibitors of oxidative phosphorylation acting as antagonists of ATP production from ADP through the mitochondrial membrane. This can cause increased consumption of glucose and inhibition of the glycogen genesis. The atractyloside, a toxic reagent was revealed by analysis of urine and gastric pump liquid using silica gel thin layer chromatography (Masri et al., 2009).

In this study, two other plants namely; E. resinifera and A. absinthium, caused each, one death. W. saharae, $R$. communis and $R$. officinalis caused each, one case of poisoning; $M$. automnalis caused 2 cases of poisoning; $C$. tinctorius and $P$. harmala caused each, 3 cases of poisoning.

\section{Conclusion}

The performed analysis allowed us to acquire a general understanding of this kind of poisoning. The most concerned age group, the symptoms presented by poisoned patients and various species of plants involved in these poisonings was also determined. This study highlights the high number of poisoning by plants in the Taza-Al Hoceima-Taounate region. A significant percentage of these poisonings could be prevented by a better awareness building among the population, especially for children about the danger of consumption of some plant species without knowledge.

\section{References}

Aarons,D.H., Rossi, G.V., Orzechowsky, R.F. 1977. Cardiovascular actions of three harmala alkaloids: harmine, harmaline and harmanol. Journal of Pharmaceutical Sciences, 66: 1244-1248.

Appendino, G., Szallasi, A. 1997. Euphorbium: modern research on its active principle, resiniferatoxin, revives an ancient medicine. Life Sciences, 60: 681-696.

Bagnis, C., Deray, G., Baumelou, A., Le Quintrec, M., Vanherweghem, J.L. 2004. Herbs and the kidney. American Journal of Kidney Diseases, 44: 1-11.

Bellakhdar, J.1997. The Traditional Moroccan Pharmacopoeia. Ancient Arabic Medicine and Popular Knowledge, 764 pp., Ibis Press, Paris, France.

Benkirane, R. 1994. Lintoxication auchardona glue poisoning by Atractylis gummifera L. Medical Esperance, 8: 49-50. 
Bonkovsky, H.L., Cable, E.E., Cable, J.W., Donohue, S.E., White, E.C., Greene, Y.J. 1992. Porphyrogenic properties of the terpenes camphor, pinene and thujone (with a note on historic implications for absinthe and the illness of Vincent vorn gogh). Biochemical Pharmacology, 43: 2359-2368.

Cazin, F.J. 1876. Absinthe. Artemisia absinthium L. In: Reasoned and Practical Treatise of Native Plants and Acclimatized. P. Asselin,(ed.), vol. 4, pp. 1-8, Paris, France.

Chardon, G., Viala, A., Vignais, P., Stanislas, A. 1964. Atractylis gummifera poisoning. Thérapie, 19: 1313-1322.

Charnot, A. 1945. La toxicologie au Moroc. Memoire de La Societe des Science naturelles du Moroc. Emile Larso, pp. 572-598, Paris, France.

Flesch, F. 2005. Plant poisoning. Medico-surgical Encyclopedia Medicine, 2: 532-546.

Fournier, P. 1947. Absinthe. Artemisia Absinthium L. In: The Book of Medicinal and Poisonous Plants of France. Paul Lechevalier (edition), vol. 1, pp. 115-120, Paris, France.

Hami, H., Soulaymani, A., Ouammi, L., Rhalem, N., Badri, M., Mokhtari, A., Soulaymani B.R. 2011. Poisoning by Atractylis gummifera L. Data of the Poison Control Center and Pharmacovigilance of Morocco. Bulletin of the Exotic Pathology Society, 104: 53-57.

Hamouda, C., Hdhili, A., Ben Salah, N., Zhioua, M., Amamou, M. 2004. A review of acute poisoning from Atractylis gummifera. Veterinary and Human Toxicology, 46: 144-146.

Kairis, M. 1996. Hepatotoxicity due to Atractylis gummifera. Hellenic Archives of Pathology, 10: 38-40.

Lengani, A., Fulbert, L.L., Innocent Pierre, I.G., Nikiema, J. 2010. Traditional medicine in kidney diseases in Burkina Faso. Nephrology \& Therapeutic, 6: 35-39.

Masri, W., Abderrazek, H., Mouldi, A. 2009. Atractylis gummifera L. Poisoning: about two clinical cases. French Review of Laboratories, 413: 87-91.

Meyer, F. 1989. Toxicity of Berries and Berry-like Fruits, 15 Years Experience of the Poison Control
Centre of Lyon. Medicine Thèse, Claude BernardLyon I, France.

Ouammi, L., Rhalem, N., Aghandous, R., Semllali, I., Badri, M., Jalal, G., Benlarabi, S., Mokhtari, A., Soulaymani, A., Soulaymani, B.R. 2009. Epidemiological profile of poisonings in Morocco from 1980 to 2007. Toxicologie Maroc, 1: 8-13.

Paris, R.R., Moyse, H. 1976-1981. Medical Matter. 3 volumes, Masson edition, 420, 509 and 518 pp., Paris, France.

Pelt, J.M. 1971. Drugs and Magical Plants, 235 pp., Horizon de France, Paris, France.

Ramaut, J.L., Hofinger, M., Dimbi, R., Corvisier, M., Lewalle, J. 1985. Main constituents of the essential oil of Warionia saharae Benth and Coss. Chromatographia, 20: 193-194.

Salas, J., Bureo, P., Cubero, J.J., Bueno, C., Caravaca, F., Pérez Miranda, M. 1985. Poisoning by Atractylis gummifera L. in Badajoz (Spain). Botany Studies, 4: 201-204.

Santi, R., Cascio, G. 1955. Research on the pharmacological active ingredient of Atractylis gummifera. Italian Archive of Pharmacological Sciences, 5: 354-363.

Soulaymani, A., Rhalem, N., Mokhtari, A., Soulaymani, B., R. 2006. Epidemiology of poisoning by plants. Experience of the Poison Control Center of Morroco from 1992 to 2000. Pharmacien d'Afrique, 193: 3-9.

Skalli, S., Alaoui, A., Pineau, A., Zaid, A., Soulaymani, B.R. 2002. Poisoning by Atractylis gummifera L. about one clinical case. Bulletin de Société de Pathologie Exotique, 95: 284-286.

Vallejo, J.R., Pardo de Santayana, M., Peral P.D., Carrasco R.M.C., López, C.D. 2008. Usomedicinal of Atractylis gummifera L. Leader in the Guadiana (Badajoz, Spain). Toxicity and related species. Journal of Phytothrapy, 8: 161-169.

Vogt, D.D. 1981. Absinthium: a nineteenth-century drug of abuse. Journal of Ethnopharmacology, 4: 337-342.

Zain, N., Guemouri, L., Lamnaouer, D., Benjouad, A. 2008. Study of four cases of poisoning by Atractylis gummifera L. in Morocco. Therapie, 63: 49-54. 